\title{
SARS-CoV-2 prevalence in 1170 asymptomatic Norwegian youths
}

\author{
Einar Kristian- Borud ${ }^{1}$, Espen Nakstad ${ }^{2}$, Siri E Håberg ${ }^{3}$, Andreas Lind ${ }^{2}$, Elin Anita \\ Fadum $^{4}$, Arne Michael Taxt ${ }^{2}$, Anneke Steens ${ }^{3}$, Gaute Gjein ${ }^{4}$, Magne Wiken Sunde ${ }^{4}$, Petter \\ Iversen $^{4}$, Marius Svanevik ${ }^{4}$, Babar Mushtaq Ahmad ${ }^{4}$, Thomas Waldow ${ }^{4}$, and Arne Johan \\ Norheim $^{4}$ \\ ${ }^{1}$ UiT The Arctic University of Norway \\ ${ }^{2}$ Oslo University Hospital \\ ${ }^{3}$ Norwegian Institute of Public Health \\ ${ }^{4}$ Norwegian Armed Forces
}

August 4, 2020

\begin{abstract}
Background Accurate estimates of SARS-CoV-2 infection in different population groups are important for the health authorities. In Norway, public infection control measures have successfully curbed the pandemic. Military training and service are incompatible with these measures, and therefore stricter infection control measures were necessary in the Norwegian Armed Forces. We present the measures, and discuss the results and their value. We report on the seroprevalence of SARS-CoV-2 and the changes in antibody levels over six weeks. Methods In April 2020, 1170 healthy conscripts (median age 20 years) were enrolled. The infection control measures included a pre-enrollment telephone interview and self-imposed quarantine. Questionnaire data and serial SARS-CoV-2 PCR and serology testing were used to estimate the incidence of confirmed SARS-CoV-2, describe symptoms and monitor titer levels over a six week period. Results The seroprevalence of SARS-CoV-2 was $0.6 \%$. Only 0.2 $\%$ had a positive PCR for SARS-CoV-2 at the enrollment day. Serological titer levels increased up to nearly five-fold over the observation period. Eighteen conscripts reported mild respiratory symptoms during the 14 days prior to enrollment (all were PCR negative, one had positive serology), whereas 17 conscripts reported respiratory symptoms and nine had fever at the day of enrollment (all were PCR and serology negative). Conclusions The prevalence of SARS-CoV-2 in young adults in Norway is less than $1 \%$. Testing of asymptomatic conscripts seems of no value in times of low COVID-19 prevalence. SARS-CoV-2 antibody titer levels increased substantially over time in youths with mild symptoms.
\end{abstract}

\section{Introduction}

Current knowledge suggests that children and young adults infected with SARS-CoV-2 are more often asymptomatic, or have fewer and milder symptoms than older patients ${ }^{1-3}$. Children and teens between 10 and 19 years may be more likely to spread the virus among family members than adults and younger children 4. As PCR testing is mainly performed on symptomatic patients, those in need of hospitalization, patients at risk, and among health care workers, the prevalence and rate of transmission in young asymptomatic individuals is still largely unknown. So far, SARS-CoV-2 testing has not been performed systematically on asymptomatic groups. Accurate estimates of infection within different population groups is crucial for health authorities when deciding how and when to close and reopen societies during the COVID-19-pandemic.

Military service in Norway is mandatory for all men and women, and annually between 7000 and 8000 conscripts undergo military conscription ${ }^{5}$. Enrollment of new conscripts is a continuous process within the Norwegian Armed Forces to secure redundancy of troops. In Norway, public infection control measures 
have successfully curbed the rates of hospital admissions and deaths by COVID-194. Military training and service are not compatible with public COVID-19 infection control measures, as service personnel live close together in barracks, and combat training involves body contact. To ensure military training and the health of military personnel, stricter infection control measures to detect and prevent SARS-CoV-2 transmission within the Norwegian Armed Forces were implemented before and at enrollment to military service in midApril 2020. The measures included a pre-enrollment telephone interview and self-imposed quarantine before enrollment, as well as serial SARS-CoV-2 PCR and serology testing during a six weeks training period.

We present the results and discuss the value of the extended infection control measures applied by the Norwegian Armed Forces Joint Medical Services in April 2020.

We also present the seroprevalence of SARS-CoV-2 in 1170 young military conscripts and the dynamic changes in antibody levels over six weeks.

\section{Materials and methods}

\section{Cohort}

Between $19^{\text {th }}$ and $27^{\text {th }}$ April 2020, 1170 military conscripts, 798 men (68. 2\%) and 372 women (31. 8 $\%$ ) were enrolled. Median age was 20 years (range $18-25$ ). As conscripts are called for military service regardless of residential area, our cohort included men and women from all over Norway.

\section{Extended systematic infection control measures}

The infection control measures performed by the Norwegian Armed Forces Joint Medical Services are visualized in Figure 1.

\section{Pre-enrollment measures}

Two weeks prior to enrollment, the conscripts were interviewed by telephone to motivate for military service and ensure compliance with infection control measures related to COVID-19. All conscripts were encouraged to conduct a self-imposed quarantine until enrollment.

\section{Enrollment day questionnaires and examinations}

Initially on the enrollment day, each conscript was asked about current respiratory symptoms, and body temperature was measured using an ear thermometer. Individuals with symptoms and/or temperature [?] $38,00 \mathrm{C}$ were further interviewed and clinically examined, and were then quarantined pending the results of the PCR virus test (Figure 1).

All conscripts had to respond to an online questionnaire, focusing on possible or confirmed COVID-19 over the past two weeks, compliance with public infection control measures and possible close contact with SARS-CoV-2 infected individuals.SARS-CoV-2 PCR specimen detection

At the enrollment day, nasopharyngeal swabs for SARS-CoV-2 PCR specimen detection were collected. PCR-tests were also performed after three and six weeks of military training. The PCR tests were analyzed at the Department of Microbiology at Oslo University Hospital using a Roche Cobas SARS-CoV-2 RNA test on the Cobas 6800 platform (Roche Diagnostics).

\section{SARS-CoV-2 serologic analyses}

Venous blood was sampled using VACUETTE\&, Blood Collection Tubes (Greiner bio-one) for SARS-CoV2 serologic testing. Serologic tests were analyzed at the Department of Microbiology at Oslo University Hospital using Elecsys $(\mathbb{R}$ anti-SARS-CoV-2 IgM/IgG assay fully automated on the Cobas e801 analyzer 
(Roche Diagnostics). The assay measures the combined total of IgM and IgG against the nucleocapsid (N) structural protein of SARS-CoV-2 and provides results as a cutoff index (COI) calculated based on signal sample / assay cutoff. A COI above 1, 2 was defined as a positive result.

Figure 1

\section{SARS-COV-2 antibody rapid-test}

Capillary blood was sampled for the Acro 2019-nCoV IgG/IgM rapid antibody test (Acro Biotech, Inc.) at the enrollment day only, and the test was performed on site. This rapid-test is a lateral flow chromatographic immunoassay for qualitative detection of IgG and IgM antibodies to SARS-CoV2. Individuals with a positive rapid-test went through a clinical interview and examination, and were quarantined, pending the results of the PCR virus test (Figure 1).

\section{Ethics}

Data from the extended systematic infection control are administered by the Norwegian Armed Forces Health Registry (NAFHR). The NAFHR is a central health registry with data from Norwegian Armed Forces personnel, including conscripts and civilian and military staff employed by the Armed Forces. The regulations for the Norwegian Armed Forces Health Registry authorizes the NAFHR to produce statistics and research in anonymous form ${ }^{6}$.

\section{Results}

\section{Enrollment day questionnaires and examinations}

On the enrollment day, 17 (1. $4 \%$ ) of the 1170 conscripts reported having mild respiratory symptoms, and in addition nine conscripts $(0,8 \%)$ had body temperature [?] 38, $00 \mathrm{C})$. None of these 26 were SARS-CoV-2 PCR positive or SARS-CoV-2 serology positive.

In the web-based questionnaire, 18 conscripts $(1.5 \%)$ reported mild respiratory symptoms during the past 14 days prior to enrollment. Reported symptoms included runny nose and sneezing (72\%), stuffy nose (61 $\%$ ), cough (55\%), sore throat (33\%), headaches (33\%), shortness of breath (16\%), fever (13\%), reduced sense of taste or smelling (11\%), sore muscles (11\%) and dizziness (6\%). None of these 18 conscripts were SARS CoV-2 PCR positive, but one had positive SARS CoV-2 serology at enrollment.

Nine conscripts (0.8\%) answered "yes" to the question "do you think you have had COVID-19". Among these, four conscripts were SARS-CoV-2 serology positive and one was PCR positive.

\section{SARS-CoV-2 PCR specimen detection}

Two of the 1170 conscripts had positive PCR tests at enrollment and one conscript with initial negative tests, tested positive at week six (Table 1). None of these reported any symptoms during the two weeks prior to or at enrollment, nor during the service period. However, based on the clinical interview, the two conscripts who tested positive at enrollment reported illness with symptom onset four and seven weeks prior to enrollment, respectively. The individual who tested positive in week six had not been ill, nor had he had any symptoms before or during the six-week observation period.

Table 1

Figure 2 


\section{SARS-CoV-2 serologic analyses}

A total of eight conscripts were SARS CoV-2 serology positive during the six-week observation period, one female and seven males. Seven conscripts (0.6\%) were SARS-CoV-2 serology positive at the day of enrollment (Table 1), including the three conscripts with PCR-positive results for SARS-CoV-2 described above. One conscript with negative PCR-tests and a negative SARS-CoV-2 serology at enrollment developed positive and rising titers at week three and six.

None of these eight conscripts had fever or reported respiratory symptoms at the enrollment day, nor did they report any respiratory symptoms during the service period. One of the eight reported mild respiratory symptoms during the two weeks prior to enrollment. However, based on the clinical interview, six of the eight conscripts with positive serology had been ill with symptom onset three to seven weeks before enrollment (Table 1).

Antibody titers increased up to almost five-fold in all but one of the seropositive conscripts during the six weeks observation period (Table 1 and Figure 2).

\section{SARS-CoV-2 antibody rapid-test}

Of the 1170 conscripts, seven were both rapid-test IgG-positive and serology-positive (Table 1), while none of them were rapid-test-negative and serology-positive. Based on the serological test at Oslo University Hospital as the gold standard, the sensitivity of the rapid- test was calculated to $100 \%$. Two conscripts of the 1170 tested both IgG and IgM positive on the rapid-test, 25 tested IgM positive and 29 tested IgG positive. Hence, a total of 56 conscripts tested either IgG, IgM or IgG and IgM positive on the rapid-test. Forty-nine of these 56 conscripts were serology-negative, whereas 1114 were both serology and rapid-test negative. A total of 1163 were consequently serology-negative, and the specificity of the rapid-test was calculated to be $96 \%$.

In this cohort, with a seroprevalence of SARS-CoV-2 of $0.6 \%$, the positive predictive value of the rapid-test was calculated to be $13 \%$.

\section{Discussion}

In this study of 1170 healthy conscripts, the sero-prevalence of SARS-CoV-2 was 0.6\%, and 0. $2 \%$ had a positive PCR for SARS-CoV-2 at the day of enrollment to military service. Eighteen conscripts reported mild respiratory symptoms during the 14 days prior to enrollment (all were PCR negative, one had positive serology), whereas 17 conscripts reported respiratory symptoms and nine had fever at the day of enrollment (all were PCR and serology negative). These low numbers may partly be due to the high awareness of infection control rules in the Norwegian population during the study period which was 3-4 weeks after the pandemic peaked in Norway in ultimo March/primo April 2020.

\section{SARS-CoV-2 PCR specimen detection}

Two conscripts had a positive PCR test at enrollment, and one had a positive PCR after six weeks. Whether this represents ongoing or previous sub-clinical infection is up to debate. The PCR assay detects the presence of viral RNA. Whether positive SARS-CoV-2 PCR represent viable and contagious virus or only viral remnants might vary depending on patients and stages of disease. A study found that the infectivity peaked three days after symptom onset, and it was not possible to culture virus from samples obtained more than eight days after symptom onset ${ }^{7}$. 


\section{Seroprevalence and serodynamics}

Eight of the 1170 conscripts $(0.7 \%)$ were seropositive for SARS CoV-2 IgG during the observation period. As antibodies against SARS-CoV-2 can be detected in the middle and later stages of the COVID-19 illness ${ }^{8}$, testing may help confirm COVID-19 diagnoses in individuals who have not previously been referred to PCR testing. Systematic antibody testing may also shed light on the actual prevalence of COVID-19 in the general population, and thus their immunisation status, which is key to the overall pandemic response in most countries. Recent studies have revealed prevalence numbers in the range of 1-5\% in European countries

9. Our results indicate that the prevalence of Covid-19 among young asymptomatic adults in Norway is less than $1 \%$, which coheres with recent mathematical estimates from the Norwegian Institute of Public Health 10 .

Six of eight seropositive conscripts, among them two with a positive PCR-test, had a history of symptoms compatible with COVID-19, with symptom onset between three and seven weeks before enrollment. Titer levels increased up to nearly five-fold over the six weeks observation period. No new symptoms were reported during this period. Most people infected with SARS- CoV-2 display an antibody response between 10 and 14 days after infection, however, the antibody response may depend on disease severity ${ }^{11}$. In some mild cases, detection of antibodies is only possible a long time after symptoms, and in a few cases, antibodies are not detected at all, at least during the time scale of the reported studies ${ }^{12}$. The duration of antibody response is still unknown, but it is known that antibodies to other coronaviruses wane over time (range: 12 -52 weeks from the onset of symptoms) ${ }^{12}$. A study found that SARS-CoV-2 IgM and IgG antibody levels may remain over the course of seven weeks after onset of symptoms ${ }^{13}$.

The symptoms and disease reported by the six seropositive conscripts were mild. COVID-19 is considered a generally mild disease in adolescents ${ }^{2,3,14}$. One of the questions that need further study is to what extent young COVID-19-patients actually present with no symptoms at all, which may increase the risk of spreading the virus to others. Our study confirms that symptoms are generally mild among young adults, but hardly supports the idea of frequent occurrence of asymptomatic spreaders, at least not in Norway ${ }^{1}$.

\section{SARS-CoV-2 antibody rapid-test}

The sensitivity and specificity of the rapid-test used in this study were $100 \%$ and $96 \%$, respectively. The relatively large proportion of false positive rapid-tests is probably partly due to the fact that the instructions given from the manufacturer recommended that "The intensity of the color in the test line regions may vary depending on the concentration of SARS-CoV-2 antibodies present in the specimen. Therefore, any shade of color in the test line region should be considered positive" ${ }^{15}$. This may have resulted in negative tests being interpreted as positive based on nearly invisible lines in the test field, and illustrates that adequate instruction and training of health personnel is crucial when introducing and using new rapid-tests.

The Acro rapid-test has recently been evaluated by the Norwegian Organization for Quality Improvement of Laboratory Examinations ${ }^{16}$, and was rated "acceptable", with a sensitivity of 0.88 and a specificity of 0.99 .

\section{Value of testing and self-reported data}

In our study, asymptomatic testing did not identify any individuals suspected of active transmission, as both conscripts with a positive PCR at enrollment had been symptom-free for more than 20 days when tested. Seven of eight conscripts with a positive serology during the study period had been symptom-free for at least 14 days before enrollment.

Testing of symptomatic conscripts, on the other hand, is widely recommended ${ }^{17}$ and used as both as a diagnostic tool and a screening method to detect cases of COVID-19 in outbreak areas. The incidence numbers in Norway have been $<5 \%$ throughout the pandemic. Symptomatic testing in this cohort did not confirm SARS-CoV-2 in any of the 26 conscripts who reported having mild respiratory symptoms or had fever at enrollment. 
Only one of the eight people with positive serology reported respiratory symptoms during the 14 days before enrollment. Given the reported time of symptom onset among the conscripts with positive serology, five of these would probably have been contagious if they had been enrolled a month earlier and three might have presented symptoms of COVID-19. Self-reported data and questionnaires therefore may have potential to be effective tools in detecting COVID-19, especially in combination with symptom-based testing. Asymptomatic testing does not seem justified given the low prevalence and corresponding low predictive value of tests in this cohort of young healthy conscripts.

\section{Conclusion}

The prevalence of SARS-CoV-2 in young adults in Norway is less than $1 \%$. Self-reported symptoms and questionnaires may prove useful in detecting COVID-19, especially in combination with symptom-based testing. Asymptomatic testing seems of no value in times of low COVID-19 prevalence. SARS-CoV-2 antibody titer levels increased substantially over time in young adults with relatively mild symptoms.

\section{References}

1. Bai Y, Yao L, Wei T, et al. Presumed Asymptomatic Carrier Transmission of COVID-19. Jama. 2020;323(14):1406-1407.

2. Devulapalli CS. COVID-19 - a mild disease in children. Tidsskrift for den Norske laegeforening : tidsskrift for praktisk medicin, ny raekke. 2020;140(6).

3. Wu Z, McGoogan JM. Characteristics of and Important Lessons From the Coronavirus Disease 2019 (COVID-19) Outbreak in China: Summary of a Report of 72314 Cases From the Chinese Center for Disease Control and Prevention. Jama. 2020.

4. Park YJ, Choe YJ, Park O, et al. Contact Tracing during Coronavirus Disease Outbreak, South Korea, 2020. Emerg Infect Dis.2020;26(10).

5. Forsvarets aarsrapport 2020. Norwegian Armed Forces. https://forsvaret.no/aarsrapport/statistikk/conscriptell. Published 2020. Accessed2020.

6. Forskrift om innsamling og behandling av opplysninger i Forsvarets helseregister. In. Oslo: The Royal Norwegian Ministry of Defense; 2005.

7. Bullard J, Dust K, Funk D, et al. Predicting infectious SARS-CoV-2 from diagnostic samples. Clinical infectious diseases : an official publication of the Infectious Diseases Society of America.2020.

8. Sethuraman N, Jeremiah SS, Ryo A. Interpreting Diagnostic Tests for SARS-CoV-2. Jama. 2020.

9. Pollán M, Pérez-Gómez B, Pastor-Barriuso R, et al. Prevalence of SARS-CoV-2 in Spain (ENE-COVID): a nationwide, population-based seroepidemiological study. Lancet. 2020.

10. COVID-19 Ukerapport Norwegian Institute of Public Health. https://www.fhi.no/publ/2020/koronavirusukerapporter/. Published 2020. Accessed 25.05, 2020.

11. Seow J, Graham C, Merrick B, et al. Longitudinal evaluation and decline of antibody responses in SARS-CoV-2 infection. medRxiv.2020:2020.2007.2009.20148429.

12. Kellam P, Barclay W. The dynamics of humoral immune responses following SARS-CoV-2 infection and the potential for reinfection. The Journal of general virology. 2020.

13. Xiao AT, Gao C, Zhang S. Profile of specific antibodies to SARS-CoV-2: The first report. The Journal of infection.2020;81(1):147-178.

14. Götzinger F, Santiago-García B, Noguera-Julián A, et al. COVID-19 in children and adolescents in Europe: a multinational, multicentre cohort study. 2020. 
15. 2019-nCoC IgG/IgM Rapid Test Cassette Package Insert. Acro Biotech Inc. https://www.assaygenie.com/content/Acro\%20Biotech/ACRO\%20Pack\%20Insert.pdf. Published 2020. Accessed2020.

16. Evaluation of 17 rapid tests for detection of antibodies against SARS-CoV-2. Oslo: Norwegian Organization for Quality Improvement of Laboratory Examinations;2020.

17. Testkriterier for koronavirus (coronavirus). Norwegian Institute of Public Health. https://www.fhi.no/nettpub/coronavirus/testing-og-oppfolging-av-smittede/testkriterier/?term=\&h=1.

Published 2020. Accessed2020.

Table 1. Test results, days from onset of symptoms to enrollment, symptom description and disease duration for the eight conscripts with positive serology. W0 = enrollment day, W3 = week three, $\mathrm{W} 6=$ week six. COI $=$ Cutoff Index. COI for postive test $=1.2$

\begin{tabular}{|c|c|c|c|c|c|c|c|c|c|}
\hline ID & $\begin{array}{l}\text { Rapid- } \\
\text { test } \\
\text { IgG }\end{array}$ & PCR W0 & PCR W3 & PCR W6 & $\begin{array}{l}\text { Sero COI } \\
\text { W0 }\end{array}$ & $\begin{array}{l}\text { Sero COI } \\
\text { W3 }\end{array}$ & $\begin{array}{l}\text { Sero COI } \\
\text { W6 }\end{array}$ & $\begin{array}{l}\text { Time } \\
\text { since } \\
\text { symptom } \\
\text { onset at } \\
\text { W0 }\end{array}$ & Symptoms \\
\hline 1 & pos & neg & neg & neg & 57.4 & 66.0 & 51.7 & 48 days & $\begin{array}{l}\text { Dry } \\
\text { cough }\end{array}$ \\
\hline 2 & pos & neg & neg & neg & 19.6 & 24.3 & 27.0 & 33 days & $\begin{array}{l}\text { Headache, } \\
\text { fatigue, } \\
\text { dry } \\
\text { cough, } \\
\text { stuffy } \\
\text { nose, } \\
\text { nausea }\end{array}$ \\
\hline 3 & pos & neg & neg & neg & 19.2 & 67.8 & 92.3 & 22 days & $\begin{array}{l}\text { Loss of } \\
\text { taste } \\
\text { and } \\
\text { sense } \\
\text { of } \\
\text { smell, } \\
\text { a little } \\
\text { headache }\end{array}$ \\
\hline 4 & pos & pos & neg & neg & 19.2 & 62.1 & 89.1 & 30 days & $\begin{array}{l}\text { Sore } \\
\text { throat, } \\
\text { cough, } \\
\text { headache, } \\
\text { heavy } \\
\text { breath- } \\
\text { ing } \\
\text { during } \\
\text { activ- } \\
\text { ity, loss } \\
\text { of taste } \\
\text { and } \\
\text { sense } \\
\text { of } \\
\text { smell }\end{array}$ \\
\hline
\end{tabular}




\begin{tabular}{|c|c|c|c|c|c|c|c|c|c|}
\hline ID & $\begin{array}{l}\text { Rapid- } \\
\text { test } \\
\text { IgG }\end{array}$ & PCR W0 & PCR W3 & PCR W6 & $\begin{array}{l}\text { Sero COI } \\
\text { W0 }\end{array}$ & $\begin{array}{l}\text { Sero COI } \\
\text { W3 }\end{array}$ & $\begin{array}{l}\text { Sero COI } \\
\text { W6 }\end{array}$ & $\begin{array}{l}\text { Time } \\
\text { since } \\
\text { symptom } \\
\text { onset at } \\
\text { W0 }\end{array}$ & Symptoms \\
\hline 5 & pos & neg & neg & pos & 18.7 & 20.3 & 23.2 & Not ill & $\begin{array}{l}\text { No } \\
\text { symptoms }\end{array}$ \\
\hline 6 & pos & pos & neg & neg & 16.2 & 40.4 & 52.0 & 49 days & $\begin{array}{l}\text { Stuffy } \\
\text { nose, } \\
\text { slight } \\
\text { cough, } \\
\text { re- } \\
\text { duced } \\
\text { taste }\end{array}$ \\
\hline 7 & pos & neg & neg & neg & 2.1 & 2.9 & 7.4 & 39 days & $\begin{array}{l}\text { Fever, } \\
\text { fatigue, } \\
\text { runny } \\
\text { nose, } \\
\text { headache, } \\
\text { chest } \\
\text { pain, } \\
\text { muscle } \\
\text { pain }\end{array}$ \\
\hline 8 & neg & neg & neg & neg & 0.6 & 1.5 & 1.6 & Not ill & $\begin{array}{l}\text { No } \\
\text { symptoms }\end{array}$ \\
\hline
\end{tabular}

Figure 1. Extended systematic infection control measures in the Norwegian Armed Forces.

Figure 2. Titers of SARS CoV-2 IgG antibodies at enrollment (week 0), week 3 and week 6 for the eight conscripts with positive serology. ID numbers correspond to table 1. 


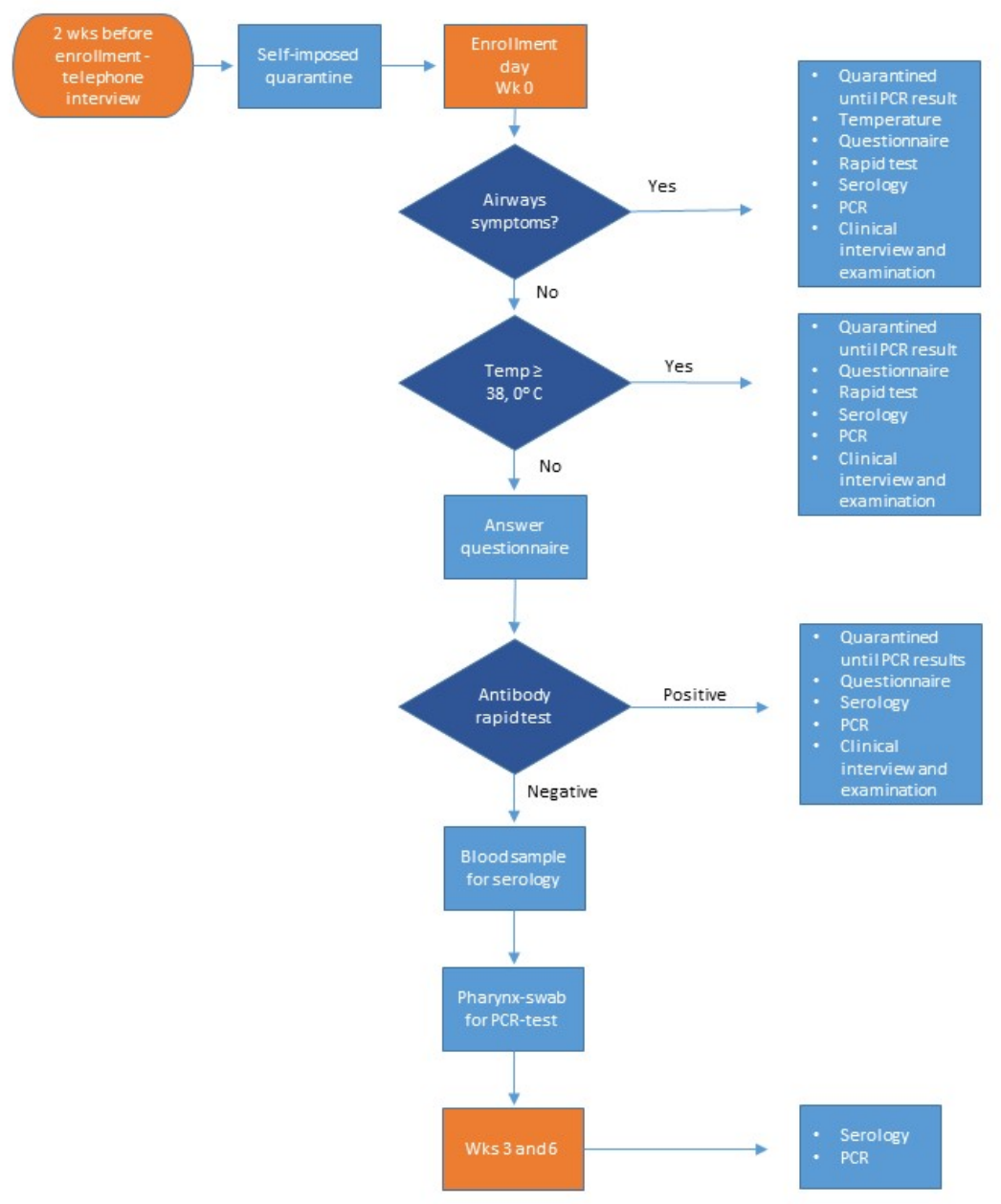




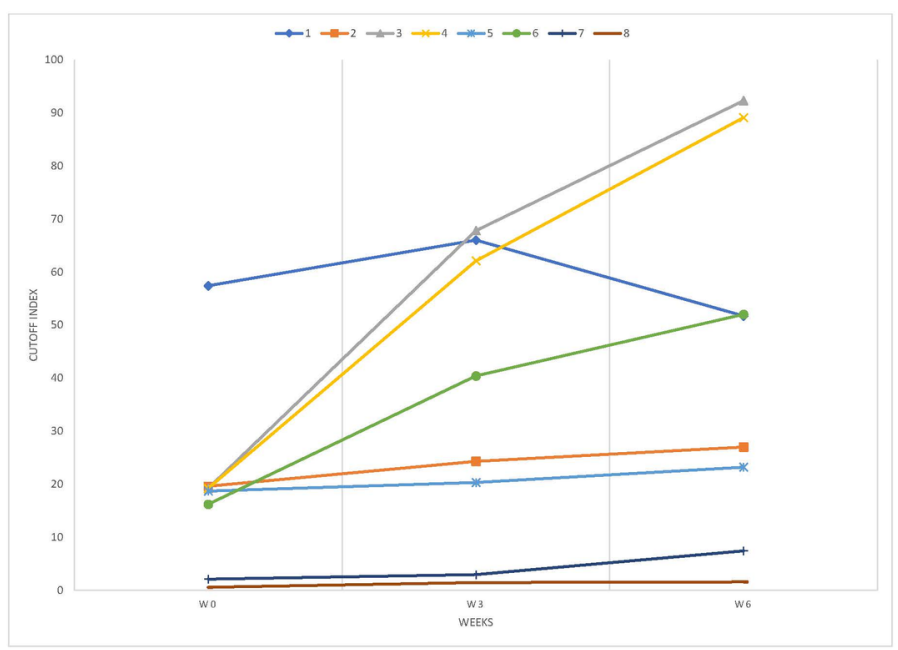

